and gentamicin-resistant Enterobacter cloacae. J Hosp Infect 1991;18: 211-8.

14 Bartzokas CA, Gibson MF, Graham R, Pinder DC. A comparison of triclosan and chlorhexidine preparations with 60 per cent isopropyl alcohol for hygienic hand disinfection. J Hosp Infect 1983;4:245-55.

15 Ayliffe GAJ, Babb JR, Davies JG, Lilly HA. Hand disinfection: a comparison of various agents in laboratory and ward studies. J Hosp Infect 1988;11:226-43.

16 Zaragoza M, Sallés M, Gomez J, Bayas JM, Trilla A. Handwashing with soap or alcoholic solutions? A randomized clinical trial of it effectiveness. Am J Infect Control 1999;27:258-61.

17 Coignard B, Grandbastien B, Berrouane Y, Krembel C, Queverue M, Salomez JL, et al. Handwashing quality: Impact of a special program. Infect Control Hosp Epidemiol 1998;19:510-3.

18 Gould D. Nurses' hand decontamination practice: results of a local study. J Hosp Infect 1994;28:15-30.
19 Lund S, Jackson J, Leggett J, Hales L, Dworkin R, Gilbert D. Reality of glove use and handwashing in a community hospital. Am J Infect Control 1994;22:352-7.

20 Voss A, Widmer AF. No time for handwashing!? Handwashing versus alcoholic rub: can we afford 100\% compliance? Infect Control Hosp Epidemiol 1997; 18:205-8.

21 Paulson DS, Fendler EJ, Dolan MJ, Williams RA. A close look at alcoho gel as antimicrobial sanitizing agent. Am J Infect Control 1999;27:332-8.

22 Pittet D, Dharan S, Touveneau S, Sauvan V, Perneger TV. Bacteria contamination of the hands of hospital staff during routine patient care Arch Intern Med 1999;159:821-6.

23 Pittet D, Hugonnet S, Harbath S, Mourouga P, Sauvan V, Touveneau S, et al. Effectiveness of a hospital-wide programme to improve compliance with hand hygiene. Lancet 2000;356:1307-12.

(Accepted 18 April 2002)

\title{
Acquisition of W135 meningococcal carriage in Hajj pilgrims and transmission to household contacts: prospective study
}

\author{
Annelies Wilder-Smith, Timothy M S Barkham, Arul Earnest, Nicholas I Paton
}

The annual Islamic pilgrimage to Mecca and Medina (Hajj) attracts more than two million pilgrims from all over the world. Overcrowding provides ideal conditions for transmission of meningococci. During the Hajj 2000 an international outbreak of meningococcal disease occurred. ${ }^{1}$ This outbreak generated particular interest as it was caused by serogroup W135, which hitherto had not played a major role in epidemics. ${ }^{2}$ Furthermore, many close contacts of asymptomatic returning pilgrims were affected. ${ }^{2}$ Although vaccination can protect pilgrims against invasive disease due to W135, it does not prevent acquisition of pharyngeal carriage, which is the primary source for transmission. ${ }^{4}$ Returning pilgrims may spread the bacteria to their unvaccinated household contacts or even to the community at large. We investigated the extent of transmission of Neisseria meningitidis in Hajj pilgrims and their contacts, in order to provide evidence for developing a rational public health policy.

\section{Methods and results}

We conducted a prospective study of meningococcal carriage in Singaporean pilgrims before the Hajj 2001 and in pilgrims and their household contacts two weeks after return from the Hajj. We performed serogrouping and pulsed field gel electrophoresis on meningococcal isolates to determine the predominant serogroup and relatedness of the strains. We questioned participants about the occurrence of any symptoms of upper respiratory tract infection, use of antibiotics within the past month, and number of people in the household.

We took tonsillopharyngeal swabs from 204 Malay pilgrims at the time of vaccination with quadrivalent meningococcal vaccine (median 39 (range 18-72) days before their departure for the Hajj pilgrimage). Median age was 48 (24-74) years, and 92 (45\%) were men. Only one of these pilgrims carried $N$ meningitidis, which was identified as serogroup X.
We took repeat swabs from $171(84 \%)$ of the pilgrims at a median of 17 (1-45) days after their return from the Hajj and found 29 (17\%) to be meningococcal carriers $(\mathrm{P}<0.001$ compared with carriage rate before the Hajj) (table). Ninety five $(56 \%)$ of returning pilgrims reported cough in the preceding month, and $70(41 \%)$ reported use of antibiotics. Carriage was significantly higher in pilgrims who had not taken antibiotics $(22 / 101,22 \%)$ than in those who had taken antibiotics $(7 / 70,10 \%)(\mathrm{P}=0.045)$, but no relation existed between carriage and age, sex, or recent symptoms of upper respiratory tract infection.

Pulsed field gel electrophoresis showed 26/29 $(90 \%)$ meningococcal isolates in Hajj returnees to be a single clone, identified as serogroup W135 in most cases and related to the strains that caused Hajj associated invasive meningococcal disease in Singapore.

The returning pilgrims reported a median of 4 (110) people living in their household. The total number of contacts (non-Hajj pilgrims within the same household) was 317. We took swabs from $233(74 \%)$ of these household contacts at a median of 26 (3-45) days after the pilgrim's return to the household. The median age of household contacts was 20 (1-67) years, and 165 $(52 \%)$ were children under the age of 18 years. The prevalence of meningococcal carriage in household contacts was $8.2 \%$, of whom $42 \%$ were carrying the W135 clone (3.4\% of all household contacts). All but one of the contacts carrying the W135 clone were contacts of returning pilgrims with the W135 clone. Of the

\author{
Travellers' Health \\ and Vaccination \\ Centre, Tan Tock \\ Seng Hospital, \\ 11 Jalan Tan Tock \\ Seng, Singapore \\ 308433 \\ Annelies \\ Wilder-Smith \\ head \\ Department of \\ Pathology and \\ Laboratory \\ Medicine, Tan Tock \\ Seng Hospital \\ Timothy M S \\ Barkham \\ consultant \\ microbiologist \\ Clinical \\ Epidemiology Unit, \\ Tan Tock Seng \\ Hospital \\ Arul Earnest \\ statistician \\ Department of \\ Infectious Diseases, \\ Tan Tock Seng \\ Hospital \\ Nicholas I Paton \\ head \\ Correspondence to: \\ A Wilder-Smith \\ epvws@pacific. \\ net.sg
}

BMJ 2002;325:365-6

Meningococcal carriage in Hajj pilgrims and their household contacts. Values are numbers (percentages) unless stated otherwise

\begin{tabular}{lccc} 
& \multicolumn{2}{c}{ Pilgrims before Hajj } \\
\cline { 3 - 4 }$(\mathbf{n}=\mathbf{2 0 4})$ & $\begin{array}{c}\text { Pilgrims } \\
(\mathbf{n}=\mathbf{1 7 1})\end{array}$ & $\begin{array}{c}\text { Household contacts } \\
(\mathbf{n}=\mathbf{2 3 3})\end{array}$ \\
\hline All isolates & $1(0.5)^{*} \dagger$ & $29(17)^{*}$ & $19(8.2)$ \\
\hline W135 clone & 0 & $26(15)$ & $8(3.4)$ \\
\hline
\end{tabular}

${ }^{*} \mathrm{P}<0.001$ between pre-Hajj and post-Hajj pilgrims (McNemar test).

†Prevalence of pre-Hajj meningococcal carriage in the 171 pilgrims who returned for the post-Hajj swab was $0.6 \%$. 
26 pilgrims carrying the $\mathrm{W} 135$ clone (all from different households), six (23\%) transmitted this strain to seven contacts, of whom two were from the same household. The acquisition rate of the W135 clone in contacts of returning carriers of the same strain was 13\% (seven out of 54 contacts).

\section{Comments}

A high acquisition rate of a single clone of W135 $N$ meningitidis occurred during the 2001 Hajj pilgrimage. Many countries currently give bivalent meningococcal vaccine (covering $\mathrm{A}$ and $\mathrm{C}$ ) to Hajj pilgrims. Vaccination with the quadrivalent meningococcal vaccine (also covering W135) should become mandatory for all Hajj pilgrims and be considered for their household contacts. Transmission of this clone from vaccinated Hajj returnees to their unvaccinated household contacts was substantial, putting contacts at particular risk of developing invasive disease. Our findings support a policy of administering antibiotics to pilgrims before their return to their countries of origin to eradicate carriage and thereby protect household contacts.

We thank Fatimah Karim and Anushia Panchalingham for taking swabs, Bernard Peperstraete for logistical help, Sindhu Ravindran for performing pulsed field gel electrophoresis, and Gamini Kumarsinghe for providing some of the meningococcal isolates of clinical cases. We also thank all the pilgrims and their contacts for participating in this study.

Contributors: AW-S had the idea for the study and was responsible for study design and for collection, analysis, and interpretation of data. TMSB was responsible for the meningococcal cultures, serogrouping, and pulsed field gel electrophoresis. AE was responsible for data entry and analysis. NIP contributed to the study design and data analysis and interpretation. All authors contributed to the final manuscript. AW-S is the guarantor.
Funding: National Medical Research Council Singapore.

Competing interests: AW-S has been reimbursed by Glaxo SmithKline and Aventis for attending conferences. TMSB has been reimbursed by Oxoid, Bayer, and Bristol-Myers Squibb for attending conferences.

1 Popovic T, Sacchi CT, Reeves MW, Whitney AM, Mayer LW, Noble CA, et al Neisseria meningitidis serogroup W135 isolates associated with the et al. Neisseria meningitidis serogroup W135 isom.

2 Taha MK, Achtman M, Alonso JM, Greenwood B, Ramsay M, Fox A, et al. Serogroup W135 meningococcal disease in Hajj pilgrims. Lancet 2000;356:2159.

3 World Health Organization. Meningococcal disease, serogroup W135. Wkly Epidemiol Rec 2001;76:141-2.

4 Rosenstein NE, Perkins BA, Stephens DS, Popovic T, Hughes JM. Meningococcal disease. N Engl J Med 2001;344:1378-88.

(Accepted 13 March 2002)

\section{Corrections and clarifications}

Scientists develop more sensitive grading system for prostate cancer

In this news article by David Spurgeon (22 June, p 1476), which reported on some research published in Cancer, the page numbers for the study were wrong. The paper was in Cancer 2002;94:3141-9.

Recent developments in neurology

In this article by Samuel Wiebe and colleagues (16 March, pp 656-60), a rogue zero somehow infiltrated the text. In the third paragraph, epilepsy affects one in 100 people [not one in 1000].

Minerva

A reader has just alerted us to an error in the text accompanying the picture in the issue of 23 March ( $\mathrm{p} 736$ ), provided by M Willet. The text describes a diagnosis of "Bechet's syndrome." Such a syndrome does not exist, although Behçet's syndrome does. Behçet was a Turkish dermatologist.

\section{You can make a difference}

"Don't get stressed," said the senior nurse in charge of emergency operating theatres. "I've been here 10 years, and things have always been the same."

"Let me run this past you again," I replied, "I am the registrar on call for maxillofacial surgery, and my consultant has a patient with a fractured mandible who needs an operation. The patient has already been waiting 18 hours, and, therefore, his chances of postoperative complications have increased. It is $850 \mathrm{am}$ : I am ready to operate, you have nursing staff available, and an anaesthetist is here. However, you are reluctant to send for the patient because general surgery may have a patient to operate on that they told you about last night, but they haven't finished their ward round yet."

"Well," said the senior nurse, "the general surgery consultant told me he is only available this morning and wanted to be first on the list."

The anaesthetist interrupted jokingly, "Your time is not as expensive as his. Anyway we hand over at 9 am, so nothing much will happen for a while. Why not get some breakfast, and we will give you a call when we know what is going on?"

Everyone had been pleasant to me, but the outcome was that no patient was being treated and a lot of NHS time was being wasted, including mine. Frustrated by the inefficiency of the system, I decided not to have breakfast but write a letter to whoever was in charge. After some questioning, I found out that this was the clinical director of anaesthesia, who was part of the theatre users committee.

My letter suggested that each morning at 830 am we should have a meeting in theatres between the anaesthetist and senior nurse working in emergency operating theatres and any surgeon who had a patient to operate on in order to prioritise cases. If surgeons were on ward rounds they should delegate one of their team to attend. The first case could then be sent for before $9 \mathrm{am}$.

Feeling much better, I signed and posted the letter. The next day I showed a copy to a colleague. "You want to be careful, or you will be labelled as a troublemaker," he advised me.

A week later, I received a reply. Preparing myself for the worst, I read the letter and was delighted to find that my suggestions had been accepted. The anaesthetic handover time was to be brought forward to $830 \mathrm{am}$ and my ideas given a trial run. Some four years later the emergency theatre meeting is still going strong.

Many people tell me that in the NHS it is difficult to change things. My reply is always the same: think the problem through, come up with a solution, and then make some polite suggestions to the people in charge. Sometimes, by simply getting involved, it is easier than you think to make a difference.

A J Gibbons specialist registrar, maxillofacial surgery, Morriston Hospital, Swansea (andrew_gibbons@hotmail.com) 